\title{
A review on the pragmatic approaches in educating and learning creativity
}

Lin, Hsiu Fen

Cultural Worker International Education, Taiwan, ROC (linshowfen@yahoo.com.tw)

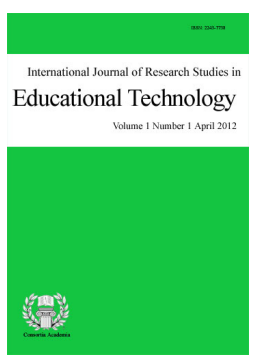

ISSN: $2243-7738$ Online ISSN: 2243-7746 OPEN ACCESS

\section{Abstract}

Current educational programs have always focused in knowledge building. However, developing ones creative skills is also considered as one of the major function of education. This paper reviews on the pragmatic approaches in educating and learning creativity. Starting from defining creativity, pragmatic techniques in learning creativity, strategies in creative education, and assessments method involved. Review concluded that creative skills can be train and develop. Future researches should try to empirically test the validity of such creative learning processes.

Keywords: creativity; literature review; pragmatic approaches; learning approaches; assessments 


\section{A review on the pragmatic approaches in educating and learning creativity}

\section{Introduction}

The pragmatic approach in creativity is not focused on scientific researchers. It is mainly concerned with developing creativity and followed by understanding it (Sternberg, 2003). Pragmatic approaches are ways to increase and use creativity and not why creativity happens (Sternberg, Lubart, Kaufman, \& Pretz, 2005). People are taught to become more creative in various practical ways with the use of practical creativity techniques. The validity of these techniques and underlying ideas has rarely been tested empirically (Chan, 2002).

Creativity techniques are replicable methods or approaches that facilitate creativity in a person or a group of people. Some famous approaches are lateral thinking (De Bono, 1971, 1985, 1992a), brainstorming (Osborne, 1953), synectics (Gordon, 1961), imaginations and false beliefs and removing mental blocks (Adams, 1974; Von Oech, 1983) and suggesting that people need to adopt the roles of explorer, artist, judge, and warrior in order to foster our creative productivity (Von Oech, 1986).

\section{Pragmatic creativity techniques}

\subsection{Lateral thinking}

In a speech in Nyenrode Business University, De Bono (2006a) said being intelligent is not enough. He also added that thinking is a skill you can develop; it is something you can learn. He distinguished three types of creativity as

$>\quad$ one that tries to find a better way of doing something,

$>\quad$ one that looks for better things to do, and

> 'crazytivity'; his word for being different without adding value (De Bono, 2006a).

Creativity in terms of new ideas and new perceptions is not a mystical gift but a learnable skill. The formal and deliberate processes of lateral thinking are all based on a consideration of the behavior of information in a self-organizing system, such as the nerve networks of the human brain. They also form asymmetric patterns: the route from A to B is not the same as the route from B to A. (Please see figures 1 and 2)

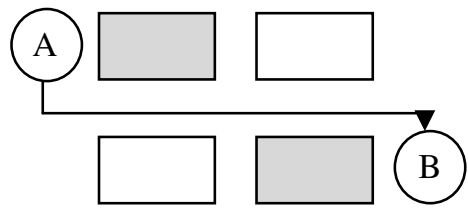

Figure 1. A to B

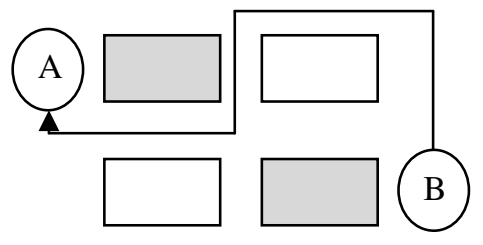

Figure 2. B to A

The formal techniques of lateral thinking include: provocation and movement; challenge; concept fans and concept triangles; random entry, etc. (De Bono, 2000, 2004a).

Lateral thinking is about changing concepts and perceptions. Certain problems do not need an injection of better logic in order to solve them; sometimes it is necessary to shift our attention, to approach the problem from a new perspective (De Bono, 2006b). Lateral thinking is also concerned with the generation of new perceptions and new ideas. It is said to be a process of changing perceptions; as in changing the way we look at things. 
A review on the pragmatic approaches in educating and learning creativity

Lateral thinking is about reasoning that is not immediately obvious and about ideas that may not be obtainable by using only traditional step-by-step logical thinking. Techniques that apply lateral thinking to problems are characterized by the shifting of thinking patterns away from entrenched or predictable thinking to new or unexpected ideas. In essence, it is considered a new idea that is the result of lateral thinking is not always a helpful one, but when a good idea is discovered in this way it is usually obvious in hindsight, which is a feature lateral thinking shares with a joke.

\subsection{Parallel Thinking with the Six Thinking Hats}

Parallel thinking with the six thinking hats is best understood in contrast to traditional argument thinking. With the tradition of argument or adversarial thinking, each side takes a different position and then seeks to prove that the other side is wrong. Argument is relied on because we believe that if you remove what is wrong; you will be left with what is right. The reality is that most arguments, and therefore meetings, result in very little constructive output at all, only bruised egos. Parallel Thinking offers a practical alternative. It encourages co-operation, exploration and innovation. With Parallel Thinking both sides, or all parties, are thinking in parallel, using the same style of thinking simultaneously. There is co-operative and coordinated thinking. The style of thinking used can be changed in order to give a balanced, objective view of the situation (De Bono, 1994a, 2000, 2006c).

A simple and practical way of parallel thinking is to use the six thinking hats method. It is an alternative to traditional argument and is far more constructive. At any moment all thinkers involved are thinking in the same direction (De Bono, 2004b). The direction is indicated by one or other of the six colored hats. The following are the concepts of De Bono (1992b, 2006c) six thinking hats.

\subsubsection{White Hat - Information known and needed}

$>\quad$ Neutral and objective

$>\quad$ Pure facts and figures

$>\quad$ The facts, just the facts

$>\quad$ First class facts: Checked and proven

$>$ Second class facts: Believed to be true

$>\quad$ Identifies information that is missing

$>\quad$ Never your own opinions

The White Hat requires an attention to information: what do we have; what do we need; what is missing.

2.2.2 Yellow Hat - Optimism: Values and benefits - Why it will work

$>\quad$ Symbolizes sunshine, brightness and optimism

$>$ Positive and constructive

$>\quad$ Probes and explores for value and benefit

$>$ Generative and supportive

$>\quad$ Strive to find logical support

$>\quad$ Speculative and opportunity seeking 
$>$ Permits visions and dreams

2.2.3 Green Hat - Possibilities, alternatives and new ideas

$>\quad$ Symbolizes fertility, growth, and the value of seeds

$>\quad$ Creative thinking

$>\quad$ The search for alternatives

$>$ Does not have to be logical

$>\quad$ Movement replaces judgment

$>\quad$ Moves from one idea to reach other ideas

$>\quad$ Generates new concepts and new perceptions

The green hat demands a focus on creative effort. When the green hat is in use everyone makes a creative effort: new ideas, alternatives, and modifications of an idea, possibilities, provocations, and many others.

2.2.4 Red Hat - Feelings hunches and intuition

$>\quad$ Legitimizes emotions and feeling

$>\quad$ This is how I feel

$>\quad$ Fears, likes, dislike, loves, hates

$>\quad$ The opposite of neutral, objective information

$>\quad$ Keep it short

$>\quad$ No need to give reasons of the basis

$>$ Allows exploring the feelings of others

2.2.5 Black Hat - Negative judgment/devil's advocate - Why it will not work

$>\quad$ Critical negative judgment

$>\quad$ Risk Analysis

$>\quad$ Logical reasons must be given

$>\quad$ Points out dangers and potential problems

$>$ Points out faults in a design

2.2.6 Blue Hat - Managing the thinking process

$>\quad$ The control hat

$>$ The orchestra conductor

$>\quad$ Organizes the thinking

$>$ Thinking about the thinking needed to explore the subject

$>\quad$ Calls for the use of other hats 
$>$ Sets the focus: Defines the problems and shapes the questions

$>$ Responsible for summaries, overviews and conclusions

$>$ Ensures that the rules are observed

\subsection{Cognitive Research Trust (CoRT)}

CoRT; named after the Cognitive Research Trust established by Dr. De Bono in Cambridge, England, it is now the most widely used course in the work for the direct teaching of thinking. Over 7 million students in over 30 countries including the United Kingdom, the United States, Canada, Australia, Japan, Singapore, Venezuela and Ireland are using it (De Bono, 2000, 2006d). The majority of mistakes in ordinary thinking (outside technical matters) are mistakes in perception. Our traditional emphasis on logic does little for perception. If the perception is inadequate no amount of excellence in logic will make up for that deficiency. Perception is a matter of directing attention. If you are not looking in the right direction it does not matter how clever you are, you will not see what you need to see (De Bono 2000, 2004c).

According to De Bono (2006d), it is generally accepted that one of the most important tasks that formal education can hope to accomplish, is to produce individuals who can think for themselves and who can become what they think they can become people who:

$>\quad$ can judge for themselves;

$>$ have developed a much greater understanding and appreciation of their own potential and that of their fellow human beings;

$>\quad$ can effectively participate in social, economical and political processes;

$>\quad$ are proactive and constructive;

$>$ have become free in far more than the political sense of the world.

The CoRT Thinking Program represents the most comprehensive approach to the teaching of thinking. It includes generative and creative thinking, operational and constructive thinking. It is used by children and adults across a broad span of age and ability levels. When used in any kind of classroom, it effects positive change in the learning environment. The thinking skill it teaches provides pupils not only with tools to improve their academic records, but also gives them real life skills. Success in using the CoRT tools does not depend on prior knowledge, a great memory, or reading or writing skills. Students of varying abilities benefit from CoRT, including special education students, gifted and talented students, ESL students, and at-risk youth.

\subsection{Why CoRT for schools?}

According to De Bono (2006e), there are 4 key reasons for the direct and explicit teaching of constructive thinking in schools.

1. The real world needs much better thinking than it is currently getting. Constructive thinking is essential for progress. Economic and social development depends on better design thinking. Most of the major problems in the world today will not be solved by analysis. There is a need to design the way forward. Many of the arguments and conflicts arise precisely from our traditional adversarial thinking habits.

2. Constructive thinking is necessary for personal life and the enjoyment of our values. The traditional ready-made solutions often no longer apply. In minds made passive by television and popular music there is very little practice of thinking. The result is behavior that is driven by peer pressure (as in 
drugs) or despair (as in suicide). Why does Australia have the highest suicide rate in the world under the age of 24 years when the quality of life is probably the best in the world? Youngsters need to be taught to think for themselves.

3. Without teaching constructive thinking skills we waste a huge amount of talent. At the age of six or seven there is one gateway, which determines whether a youngster is going to be an idiot in school, or not. This is the reading/writing gateway. For various reasons including dyslexia, ADD and other physiological factors some youngsters are slow at this gate and may be forever lost. If thinking is offered as a parallel gateway then many of these youngsters turn out to be excellent thinkers with huge effects on their self-esteem and the way others treat them. This is a very important point. Those who seemed to have failed in school but did well later in life would have done well at the thinking gateway. It is simple enough to do with the basic CoRT program.

4. The development of thinking skills helps even in schoolwork. Although the prime purpose of teaching thinking skills is for the use in real life, such skills also help in school. For example research shows that having a thinking framework for discussion helps discussion. Having attention directing tools (as in CoRT) makes it easier to explore subjects.

CoRT for Schools (De Bono, 1986a, 1986b, 2006f, 2006g):

1. CoRT 1: Breath - broadens perception by demonstrating a number of different directions thinking can follow.

Table 1

Various types of lessons and activities

\begin{tabular}{|c|c|c|}
\hline & Types of lesson & Activities \\
\hline 1 & $\begin{array}{l}\text { PMI - Plus, Minus, } \\
\text { Interesting }\end{array}$ & $\begin{array}{l}\text { Designed to ensure that decision or commitment takes place after both sides of } \\
\text { the matter have been considered and not before. }\end{array}$ \\
\hline 2 & $\begin{array}{l}\text { CAF - Consider All } \\
\text { Factors }\end{array}$ & $\begin{array}{l}\text { This operation is essentially related to action, decision, planning, judgment and } \\
\text { coming to a conclusion. }\end{array}$ \\
\hline 3 & Rules & $\begin{array}{l}\text { Provides an opportunity for practicing the two previous lessons: PMI and CAF } \\
\text { An existing or proposed rule is an opportunity for practicing PMI. } \\
\text { The factors involved in making a rule provide practice in CAF }\end{array}$ \\
\hline 4 & $\begin{array}{l}\mathrm{C} \text { and } \mathrm{S}- \\
\text { Consequence and } \\
\text { Sequence }\end{array}$ & $\begin{array}{l}\text { Crystallization of the process of looking ahead to see the consequences of some } \\
\text { action plan decision rule invention and many others. Attention is focused directly } \\
\text { on the future. Immediate, short medium and long-term consequences are } \\
\text { examined by different groups. }\end{array}$ \\
\hline 5 & $\begin{array}{l}\text { AGO - Aims Goal } \\
\text { Objectives }\end{array}$ & $\begin{array}{l}\text { This lesson provides a focus on the intentions behind actions on the idea of } \\
\text { purpose. In some situations, it is more appropriate to use aims rather than goals } \\
\text { of objectives. The key here is to focus on purpose rather than reaction. }\end{array}$ \\
\hline 6 & Planning & $\begin{array}{l}\text { The idea is to use planning as a thinking situation which brings together. } \\
\text { Objectives (AGO), consequences (C\&S), the factors involved (CAF) and the } \\
\text { treatment of ideas (PMI) }\end{array}$ \\
\hline
\end{tabular}


Table 1... continue

Various types of lessons and activities

\begin{tabular}{|c|c|c|}
\hline & Types of lesson & Activities \\
\hline 7 & $\begin{array}{l}\text { FIP - First Important } \\
\text { Priorities }\end{array}$ & $\begin{array}{l}\text { FIP is a judgment situation which requires no absolute answers. It is person, } \\
\text { and/or situation specific. It is a crystallization of the process of picking out the } \\
\text { most important ideas, factors, objectives, consequences, etc. per the requirements } \\
\text { of the specific situation. }\end{array}$ \\
\hline 8 & $\begin{array}{l}\text { APC - Alternatives, } \\
\text { Possibilities, Choices }\end{array}$ & $\begin{array}{l}\text { APC is an attempt to focus on exploring all the alternatives, choices, of } \\
\text { possibilities - beyond the obvious ones. }\end{array}$ \\
\hline 9 & Decisions & $\begin{array}{l}\text { This lesson provides an opportunity to bring together the last two lessons in } \\
\text { particular FIP and APC: } \\
\text { In making decisions you have to: } \\
>\quad \text { Consider all the factors } \\
>\quad \text { Be clear about aims/objectives } \\
>\quad \text { Assess priorities } \\
>\quad \text { Look at consequences } \\
>\quad \text { Discover alternative courses of action } \\
>\quad \text { You can also do a PMI on the decision once made }\end{array}$ \\
\hline 10 & $\begin{array}{l}\text { OPV - Other People's } \\
\text { View }\end{array}$ & $\begin{array}{l}\text { This considers the process of looking at other peoples viewpoints so that the } \\
\text { process can be used consciously and deliberately to escape from one's own point } \\
\text { of view. }\end{array}$ \\
\hline
\end{tabular}

2. CoRT 2. Organization - helps students to organize their thinking. The first five operations are basic ones concerned with moving forward from an initial idea. The second five operations concern the general organization of thinking.

3. CoRT 3: Interaction - is concerned with argument, interaction and critical thinking: the way we use to be right and the ways we can be wrong.

4. CoRT 4: Creativity - creativity is treated as a normal part of thinking processes that can be learned, practiced and applied in a deliberate manner. The purpose of creativity is to arrive at an effective new idea. CoRT 4 encourages the design type of creativity. This may be concerned with changing concepts and changing - in other words, lateral thinking.

5. CoRT 5: Information and feeling - concerned with eliciting information and assessing it. Values and emotions determine the outcome of our thinking. The purpose of thinking is to arrange the world in our minds so that we can apply values and emotion effectively.

6. CoRT 6: Action - Thinking in action, active thinking. This section is concerned with the total process of thinking: beginning with the purpose, and ending with the specific action steps for implementing the outcome of thinking. This section consolidates the thinking processes that have been explored and practiced in CoRT 1 through 5. 


\subsection{Brain storming}

Brainstorming is a group creativity technique that was designed to generate a large number of ideas for the solution of a problem. It can be a difficult process for many reasons: sometimes people are unwilling to suggest a solution for fear of criticism or the problem may just be a very difficult one, and one that no existing solutions exist for yet (Skymark, 2007).

Osborne's solution is to think up as many ideas as possible regardless of how ridiculous they may seem at first. Since it is very unlikely to think up the perfect solution right off the bat, he recommends getting every idea out of your head and then go back to examine them afterwards. An idea that may have initially sounded off-the-wall may actually turn out to be a plausible idea with a little modification. Osborne's technique of deferred judgment increases the individual's synthesis capabilities by releasing the human mind from the analysis mode of thinking. Brainstorming is considered to be a group method of listing suggested ideas pertaining to a solution for a specific problem

Some suggested that brainstorming is a technique of letting your thoughts flow out freely to come up with new and varied ideas (Gamez, 1996). Gamez (1996) further mentioned that they are four basic rules in brainstorming. These are intended to reduce the social inhibitions that occur in groups and therefore stimulate the generation of new ideas. The expected result is a dynamic synergy that will dramatically increase the creativity of the group. These suggestions are as follows:

$>$ Focus on quantity: This rule is a means of enhancing divergent production, aiming to facilitate problem solving through the maxim, quantity breeds quality. The assumption is that the greater the number of ideas generated, the greater the chance of producing a radical and effective solution.

Do criticism: It is often emphasized that in group brainstorming, criticism should be put on hold. Instead of immediately stating what might be wrong with an idea, the participants focus on extending or adding to it, reserving criticism for a later 'critical stage' of the process. By suspending judgment, one creates a supportive atmosphere where participants feel free to generate unusual ideas.

$>$ Unusual ideas are welcome: To get a good and long list of ideas, unusual ideas are welcomed. They may open new ways of thinking and provide better solutions than regular ideas. They can be generated by looking from another perspective or setting aside assumptions.

$>$ Combine and improve ideas: Good ideas can be combined to form a single very good idea, as suggested by the slogan " $1+1=3$ ". This approach is assumed to lead to better and more complete ideas than merely generating new ideas alone. It is believed to stimulate the building of ideas by a process of association.

The technique of brainstorming takes place in a panel format. The brainstorming panel is composed of a leader, recorder, and panel members. The leader is responsible for maintaining a rapid flow of ideas while the recorder lists all the ideas as they are presented. The size of the panel may vary but a range of 10 to 12 is usually enough. If the group were to get larger there is a greater chance of members remaining in the background or that the members would not have enough time to express their ideas in a reasonable amount of time. These practices are essential to any brainstorming process, but many people have criticized Osborne's methods as incomplete. For instance he does not suggest that team members prepare for brainstorming sessions. Another is that he does not offer tools or exercises in coming up with creative ideas in the first place (Skymark, 2007). 


\subsection{Synectics}

Synectics is a problem solving approach that stimulates thought processes of which the subject is generally unaware. This method, developed by William Gordon, has as its central principle: Trust things that are alien, and alienate things that are trusted. This encourages, on the one hand, fundamental problem-analysis and, on the other hand, the alienation of the original problem through the creation of analogies. It is thus possible for new and surprising solutions to emerge. Synectics is more demanding of the subject than brainstorming, as the many steps involved mean that the process is more complicated and requires more time and effort.

For some, synectics is an idea generating technique, similar to brainstorming, where the discussion is centered on a general idea that is related to a problem, rather than the problem itself (as in brainstorming); also called blue sky (Answers, 2007). In addition, Gordon (1961) set forth three fundamental precepts of synectic theory:

1. Creative output increases when people become aware of the psychological processes that control their behavior.

2. The emotional component of creative behavior is more important than the intellectual component; the irrational is more important than the intellectual component.

3. The emotional and irrational components must be understood and used as precision tool in order to increase creative output.

\section{Assessments:}

The emphasis in education has always been on logical sequential (vertical) thinking which is by tradition the only proper use of information (De Bono, 1970). With vertical thinking one makes immediate judgments, with lateral thinking one may delay judgments in order to allow information to interact and generate ideas. The twin aspects of lateral thinking are first the provocative use of information and second the challenge to accepted concepts. Underlying both these aspects is the main purpose of lateral thinking which provides a means to restructure patterns. This restructuring of patterns is necessary to make better use of information that is already available. It is an insight restructuring (De Bono, 1970). In a way, the purpose lateral thinking is to provide a more deliberate means of pattern switching than relying on mistake or accident. Lateral thinking seeks to achieve the pattern switching that occurs in insight (De Bono, 1994b).

Some suggested that synectic thinking is the process of discovering the links that unite seemingly disconnected elements. It is a way of mentally taking things apart and putting them together to furnish new insight for all types of problems (Roukes, 1988). After carefully considering the various techniques and tools proposed by De Bono's Lateral Thinking, 6 Thinking Hats, Brainstorming, CoRT, and many others (De Bono, 1970, 1971, 1985, 1986, 1992, 1994, 2000, 2004, 2006), Osborne's Brainstorming (Osborne, 1953), Gordon's Synectics (Gordon, 1961), and Von Oech Role playing (Von Oech, 1986) in the pragmatic approaches in creativity. One significant factor arises, which is the enhancing the ability of insights.

According from Merriam Webster Online Dictionary (2007), insight is the power or act of seeing into a situation; it is also the act or result of apprehending the inner nature of things or of seeing intuitively. Insights may also represent a complex phenomenon involving effort and preparation, failed initial solution attempts, restructuring of how one understands the problem situation, and the subsequent sudden emergence of an affectively laden solution with the development of the new approach (Mumford \& Whetzel, 1996). Creative success often results from recognizing that the original problem definition is hiding effective solutions, it may be advantageous to explore a definition of the creative event not as an idea that is newer and better but as $a$ shift in perspective or belief that makes new possibilities obvious (Barlow, 2001). This shift in perspective is also known as having insight. 
As Sternberg and Davidson (1995) points out, insights appears to involve problem representations and operates during encoding and concept identification, it seems reasonable to conclude that mechanisms underlying insight may well influence problem construction, encoding, and encoding, and category selection, thereby representing a phenomena capable of contributing something to our understanding of creative thought. With these in mind, some techniques in evaluating one's insight is adapted from De Bono's book Lateral Thinking - Creativity Step by Step (1970):

1. Progressive arrangement of cardboard shapes. One can make up different sort of shapes and also devise new patterns for illustrating the same thing. In addition one can ask the students themselves to devise new shapes. Example: Non-geometrical shapes. Using geometrical shapes to illustrate the deliberate search for alternatives

2. Photographs and pictures can be taken from newspapers and magazines. Students are asked to interpret a situation and give different ways of looking at a picture. Example: Describe what you think is happening in that picture or Describe three different things that could be happening in that picture.

3. Drawings of scenes or people in action can be provided by the students themselves. The complexity or accuracy of the drawing is not important since what matters is the way it is looked at.

4. Written material - stories. Stories may be obtained from newspapers or magazines or even books that are being used elsewhere in the curriculum. Students can generate different points of view of the people involved, or change what is a favorable description to an unfavorable one not by changing the material but by changing the emphasis and looking at it in a different way, or even extract a different significance from the information given than that extracted by the writer.

5. Problem solving. Problems can be generated from the inconveniences of everyday lives or by looking through newspaper. Student can be asked to generate alternative ways of stating the problem or alternative approaches to the problem.

These are only some of the sample techniques that can be use in evaluating the student's ability for making insights. In addition, one can also include puzzles from Sloane and MacHale's books Great Lateral Thinking Puzzles (1993) and Challenging Lateral Thinking Puzzles (1994).

\section{Conclusions}

The current study involves the analysis and organization of information relevant to pragmatic approaches in learning and teaching creativity. Although creativity researches are gaining popularity, but most experts are looking more on ways to stimulate creative individuals and how their environment impacted their creativity. In current days, schools need to develop the connectivity students have between their teachers and other learners. This connectivity, or creative partnership, builds the individual's creativity, enabling them to better identify the appropriate problems, and to how to solve them. In essence, the current review concluded that creative skills can be train and develop. Future researches should try to empirically test the validity of such creative learning processes.

\section{References:}

Answers (2007). Synectics. Retrieved March 24, 2007, from http://www.answers.com/topic/synectics

Adams, J. L. (1974) Conceptual blockbusting: A guide to better ideas. San Francisco: Freeman.

Barlow, C. M. (2001). Insight or Ideas: Escaping the idea centered "Box" defining creativity. Published in the Proceedings of the Hawai'i International Conference On System Sciences, January 3-6, 2001, Maui, Hawaii.

Chan, D. W. (2002) Fostering creativity in schools in Hong Kong: Issues and challenges from a systems perspective. Journal of Contemporary Chinese, 5(1). Retrieved March 25, 2007, from 
A review on the pragmatic approaches in educating and learning creativity

http://www.fed.cuhk.edu.hk/ hkier/jecc/journallist.htm

De Bono, E. (1970). Lateral thinking: Creativity step by step. New York: Harper.

De Bono, E. (1971). Lateral thinking for management: A handbook of creativity. New York: American

Management Association.

De Bono, E. (1985). Six thinking hats. Boston: Little Brown.

De Bono. E. (1986a). CoRT Thinking. Chicago: SRA.

De Bono. E. (1986b). CoRT thinking: Teacher's notes. New York: Pergamon.

De Bono, E. (1992a). Serious creativity: Using the power of lateral thinking to create new ideas. New York: Harper Business.

De Bono, E. (1992b). Six thinking hats for schools. Melbourne: Hawker Brownlow Education.

De Bono, E. (1994a). Parallel thinking. London: Viking.

De Bono, E. (1994b). De Bono's thinking course. New York: Facts on file.

De Bono, E. (2000). New thinking for the new millennium. Beverly Hills: New Millennium.

De Bono, E. (2004a). Lateral thinking. Retrieved March 25, 2007, from http://www.edwarddebono.com/concept5.htm

De Bono, E. (2004b). Parallel thinking - The six thinking hats. Retrieved March 25, 2007, from http://www.edwarddebono.com/concept6.htm

De Bono, E. (2004c). CoRT thinking lessons. Retrieved March 25, 2007, from http://www.edwarddebono.com/concept1.htm

De Bono, E. (2006a). Edward De Bono on creativity and innovation. The Netherlands: Nyenrode Business University.

De Bono, E. (2006b). Lateral thinking and serious creativity. Retrieved March 23, 2007, from http://www.edwarddebonofoundation.com/lateral.htm

De Bono, E. (2006c). Six thinking hats - One day workshop. Retrieved March 23, 2007, from http://www.edwarddebonofoundation.com/sixthinking.htm

De Bono, E. (2006d). Cognitive research trust. Retrieved March 23, 2007, from http://www.edwarddebonofoundation.com/cortforschools.htm

De Bono, E. (2006e). Why CoRT schools? Retrieved March 23, 2007, from http://www.edwarddebonofoundation.com/cort_why.htm

De Bono, E. (2006f). CoRT-1. Retrieved March 23, 2007, from http://www.edwarddebonofoundation.com/cort1.htm

De Bono, E. (2006g). CoRT-2-6. Retrieved March 23, 2007, from http://www.edwarddebonofoundation.com/cort2-6.htm

Gamez, G. (1996). Creativity - How to catch lightning in a bottle. Los Angeles: Peak.

Gordon, W. J. (1961). The development of creative capacity. New York: Harper.

Merriam-Webster. (2007). Definition of insight. Retrieved March 26, 2007, from http://www.m-w.com/dictionary/insight

Mumford, M. D., \& Whetzel, D. L. (1996). Insight, creativity, and cognition: On Sternberg and Davidson's the nature of insight. Creativity Research Journal, 9(1), 103-107. doi: 10.1207/s15326934crj0901_10 <http://dx.doi.org/10.1207/s15326934crj0901_10>

Osborne, A. F. (1953). Applied imagination. New York: Scribner.

Roukes, N. (1988). Design synectics - Stimulating creativity in design. Davis publication.

Skymark. (2007). Alex F. Osborne: Father of the brainstorm. Retrieved March 25, 2007, from http://www.skymark.com/resources/leaders/osborne.asp

Sloane, P., \& MacHale, D. (1993). Challenging lateral thinking puzzles. New York: Sterling.

Sloane, P., \& MacHale, D. (1994). Great lateral thinking puzzles. New York: Sterling.

Sternberg, R. J. (2003). Wisdom, intelligence, and creativity synthesized. New York: Cambridge University Press. <http://dx.doi.org/10.1017/CBO9780511509612>

Sternberg, R. J., \& Davidson, J. E. (1995). The nature of insight. Cambridge, MA: MIT Press.

Sternberg, R. J., Lubart, T. I., Kaufman, J. C., \& Pretz, J. E. (2005). Creativity. In K. Holyoak \& R. Morrison 
Lin, H. F.

(Eds.), Cambridge handbook of thinking and reasoning (pp. 351-369). New York: Cambridge University Press.

Von Oech, R. (1983). A whack on the side of the head. New York: Warner Books.

Von Oech, R. (1986). A kick in the seat of the pants: Using your explorer, artist, judge \& warrior to be more creative. New York: Harper Perennial. 